\title{
Everyday experiences of sexism in male-dominated professions: a Bourdieusian perspective
}

\author{
Abigail Powell ${ }^{1}$ \\ Centre for Social Impact, UNSW Australia, Australia
}

\section{Katherine J C Sang}

Intercultural Research Centre, School of Management and Languages, Heriot Watt University, UK

\begin{abstract}
Women remain under-represented in the UK engineering and construction sectors. Using a Bourdieusian lens, this paper examines the persistence of everyday sexism and gender inequality in male-dominated professions. Bringing together findings from three research projects with engineering and construction industry students and professionals, we find that women experience gendered treatment in everyday interactions with peers. Patterns of (mis)recognition and resistance are complex, with some women expressing views which reproduce and naturalise gender inequality. In contrast other women recognise and resist such essentialism through a range of actions including gender equity campaigning. Through a Bourdiesian analysis of the everyday, this paper calls into question existing policy recommendations that argue women have different skills that can be brought to the sector. Such recommendations reinforce the gendered nature of the engineering and construction sectors' habitus and fail to recognise how the underlying structures and practices of the sector reproduce gendered working practices.
\end{abstract}

Keywords: architecture, Bourdieu, construction, engineering, everyday, gender, maledominated occupations, professions, sexism 


\section{Introduction}

Despite a range of equality legislation and initiatives, the UK engineering and construction industry remains one of the most male-dominated sectors. Women are under-represented in all engineering and construction occupations and professions. Existing literature in this field primarily describes the difficulties experienced by women who work in the sector, with a focus on cultural and structural barriers, such as harassment and discrimination, limited networking opportunities and long and inflexible working hours which often result in poor career prospects and high levels of stress for women (e.g. Barnard et al., 2010; Sang and Powell, 2012). Many, if not all, of these challenges are everyday experiences for women in the sector, not isolated occurrences. As such more work is required to understand this persistent situation, exploring particularly why and how it is that men maintain 'their control of and through organizations' (Cockburn, 1991). The practice of gender is situated in everyday interactions (Budgeon, 2014), and the analysis of everyday life can reveal something about gender as a macro-level structure and process (Crow and Pope, 2008). This article addresses these issues using the work of Bourdieu to understand the everyday (re)production of gender relations in the engineering and construction professions, drawing particularly on the concepts of habitus, capital and symbolic violence.

\section{Women in male-dominated professions}

The move of women into the professions has received considerable attention within the sociological literature. The professions themselves are rooted in raced, classed and gendered notions that have historically privileged white, middle class men (Witz, 1990). Studies have demonstrated, that even where women numerically equal or outnumber men (at least in junior levels), professions maintain occupational segregation through the construction of women's difference (Bolton and Muzio, 2007). 'Gender-based discrimination and exclusionary dynamics are still everyday experiences' for women in the professions (Bolton and Muzio, 2007:49). The professions in the engineering and construction industry (including engineers, architects, designers, project managers), on which this paper focuses, are 
amongst the worse in terms of gender disparity; the industry remains largely white, male and able-bodied, despite a range of initiatives over recent decades that have sought to challenge this profile. The persistence of gender inequality in these sectors effects women's recruitment, retention and progression and is largely attributable to cultural and structural barriers (Sang and Powell, 2012). However, few studies have gone beyond this to address why these barriers are so persistent and hard to shift.

Research addressing the dominance of white men in management studies considers how organisations reproduce societal race relations (Nkomo, 1992); similar questions can be asked of the dominance of men in engineering and construction. Much of the extant literature fails to interrogate gender relations in engineering and construction. Rather it focuses on women's experiences and compares these experiences to an unexamined norm. This paper uses the work of Bourdieu, and particularly the concept of 'symbolic violence' to shed light on the continued dominance of white men in engineering and construction and how the sector (re)produces societal gender norms and relations. This builds on the work of Gracia (2009), who argues that the notion of symbolic violence provides a useful mechanism through which to understand gender inequality in the workplace.

\section{Introducing Bourdieu}

The 'habitus' in the 'field' of construction is one in which construction jobs are seen as intrinsically male. The gendered assumptions implicit in how construction work is described and carried out is rarely questioned (hence it is habitus), although can operate at both the conscious and unconscious levels (Sayer, 2005; Reay, 2004a). The habitus of construction is internalised by both women and men employed in construction, particularly those who succeed in the industry, through conscious and unconscious learned experiences. This impedes greater gender diversity since those in positions of power select those most like themselves through homosocial reproduction (Sang et al., 2014).

Bourdieu argued that 'symbolic violence' is the means through which gender inequality is reproduced (Bourdieu and Wacquant, 1992) and that such violence can be emotional, social or psychological (Gracia, 2009). Symbolic violence, is not physical, but may take the form of 
people being denied resources, treated as inferior or being limited in terms of realistic aspirations. Gender relations, for example, have tended to be constituted out of symbolic violence that has denied women the rights and opportunities available to men (Webb et al., 2002).

Bourdieu suggested that the symbolic violence of patriarchal practices embed the naturalisation of gender into individuals' identities (Gracia, 2009). 'Symbolic violence... is the violence which is exercised upon a social agent with his or her complicity... I call misrecognition the fact of recognizing a violence which is wielded precisely inasmuch as one does not perceive it as such' (Bourdieu and Wacquant, 1992). Misrecognition thus occurs when individuals 'forget' that they are produced by the social world as particular types of people. It means that social processes and structures are veiled, so that masculinity and femininity are misrecognised as natural, essentialised personality dispositions (Skeggs, 2004). Bourdieu suggests that this 'misrecognition' means that those who are dominated (i.e. women) put up with conditions that would seem intolerable to others, thus helping to reproduce the conditions of their oppression (Bourdieu, 2001). In other words, individuals are subject to symbolic violence, but do not perceive it as such, because their situation seems to be the natural order of things (Webb et al., 2002).

Feminist critiques have pointed to the lack of scope for change and women's agency within Bourdieu's theory of practice. Moi (1991) argues for the usefulness of Bourdieu's framework for understanding the continued oppression of women, specifically that continued symbolic violence forms women's habitus. Further, Bourdieu has been criticised for conflating sex, sexuality and gender and overly focussed on gender socialisation through the neglect of understanding those who resist gendered norms (Lovell, 2000).

Lovell (2000) explores the potential for Bourdieu's theory to explain the exceptional, rather than the ordinary gender order, specifically women who cross into masculine games. Women who enter male-dominated occupations could be seen as crossing this traditional boundary into masculine games. However, despite some feminist work problematizing the everyday (most notably that of Dorothy E Smith, 1987), further work is required to understand the lived experiences of such women, and the extent to which those who transgress traditional 
gendered occupational boundaries are indeed resisting gendered norms (Lovell, 2000). More broadly recent research has argued that the study of the everyday is frequently absent in sociological theorising, despite its potential to reveal the complexities of everyday experience (Pink, 2012). Researchers have begun to explore everyday life in relation to gender inequality, in particular, 'everyday sexism' (e.g. Gervais et al., 2010; Peel, 2001), a concept which has gained considerable traction within popular culture (e.g. Bates, 2014). However, it remains ill-defined within the academic literature. Everyday sexism is generally taken to refer to non-violent sexism experienced in everyday interactions (e.g. Berg, 2006; Becker and Swim, 2011). Despite Bourdieu's (1986) interest in the everyday, few studies have linked Bourdieusian theory with everyday sexism.

Our aim is to explore women's experiences, understandings and explanations of everyday gender relations within male-dominated professions/sectors. In order to avoid essentialism we view gender as a social construction (as does Bourdieu, 2001). We echo the arguments of Schippers (2007) in that that the social locations of 'man' and 'woman' are the places where characteristics of masculinity or femininity are embodied or displayed. Although Bourdieu perceived gender to be only secondary as a structuring principle of the social field, it has been argued that this 'secondary' status enhances its significance rather than diminishes it (Lovell, 2004); gender is dispersed across the social field and, though it may be hidden, is pervasive (McCall, 1992) and as such is deeply structuring (Lovell, 2004).

\section{Methods}

The paper brings together findings from three qualitative, interview-based, research projects the authors conducted examining gender amongst architects and engineers. Developing strategies for empirically investigating everyday experience can be problematic. Interviews have been demonstrated as useful for understanding how individuals make sense of their everyday lives (Pink, 2012). The combining of qualitative datasets for subsequent reanalysis remains a contentious methodological approach. However, there are increasingly acknowledgements of its value. Van den Berg (2008) argues that the combination of different qualitative datasets for collaborative research is appropriate as long as researchers share details of the process of data collection and share similar approaches. This paper uses 
datasets collected and analysed by the two authors independently, although prior analyses focussed on different research questions (Sang et al., 2014; Powell et al., 2009). Here we present fresh analyses to answer new research questions - what Hammersley (2010) refers to as a borderline case of secondary qualitative data analysis.

The use of a semi-structured interview guide meant that key issues identified by the researchers could be explored, while at the same time interviewees could define issues according to their own experiences and understanding. In total 105 interviews were conducted between 2002 and 2010. The combination of these datasets presents an opportunity to understand gender relations within male-dominated sectors across an eight year time period. The datasets comprise individuals at different stages in their careers, and working in different (but male-dominated) occupational contexts. Doing so allows for an analysis of the recurring themes across age and occupation, while retaining sensitivity to differences as they emerge through the data. Summary information from each study is detailed below:

Study 1: Interviews with 43 were women and 18 men UK undergraduate engineering and technology students. The students were in either their second or third year of university and had limited industry experience, although some had been, or were, on work-placements. Students were from a single university but a range of disciplines including: automotive and aeronautical engineering, chemical engineering, civil engineering, mechanical and manufacturing engineering, design technology and construction and transport management. None of the participants were mature-age students.

Study 2: Interviews with 10 women and 13 men architects practicing in the UK. The practising architects all had several years of industry experience (between 5 and 25 years).

Study 3: Interviews with 16 women and 5 men. Participants had between 2 and 29 years post qualification experience working in professional roles within the UK construction industry. Job titles included, project manager, civil engineer, construction law solicitor and architect. Of these participants, 9 had children. 
For each of the studies, participants were fully informed of the purpose of the research study and informed that their (anonymised) responses may be used in resulting publications. With participants' agreement, interviews were recorded, transcribed verbatim and anonymised prior to being analysed with the aid of NVivo. The datasets were combined and subjected to thematic analysis to identify themes emerging across the datasets, including tensions and contradictions within the data. The analysis was informed by the theoretical framework Bourdieu's theory of practice - while remaining sensitive to themes that emerged from the data. The authors analysed the data independently, verifying analysis with each other throughout the process. While both men and women were interviewed in the studies reported, we prioritise the perspectives and experiences of women respondents in order to present a rich analysis of their lived experiences, as they reported them. Further, while the study includes data from a range of professions within male-dominated sectors, we identify common themes across the data and highlight differences where they occur.

\section{Findings: Everyday othering}

The findings are focused around everyday distinctions of difference: examples of women being treated differently, or perceiving they were treated differently, by both male and female colleagues, managers, lecturers and clients. Some of the women interviewed discussed how they themselves treated women differently to men, or how they perceived women to be different to men, which we also reflect on. Differential treatment was not always perceived negatively, as discussed below. However, it was rare for women to challenge or resist such difference, although we highlight a few examples. A number of women in the studies, particularly the younger ones, were not aware of, had no experience of, or did not choose to disclose, being treated differently as a result of their gender. For example Rebecca, a design and technology student (study 1), reported:

I don't worry about my gender ... because like there's people around me who are quite high up who are female it doesn't ever seem ... you'd never think that there'd be an issue really. 
Nevertheless women across all studies articulated examples of where they had been treated differently to their male counterparts. Such 'othering' included exclusion and being on the receiving end of sexist humour.

\section{Othered by exclusion}

Andrea, a civil engineering student (study 1 ) described how she was excluded by her male peers from a group assignment at university. Subsequently she was marked down in the peer assessment of the assignment. Not surprisingly Andrea felt this was unfair because of the boundaries she perceived were placed on her. Exclusion from the group denied Andrea access to key resources and the opportunity to develop capital through the assessment. Women working in the sector recalled similar instances of being excluded from key events. For example, Amy, a practicing architect said that when she was an undergraduate she had been the only woman on her course and that the male students carried 'on like it's a boys' organization...they just ignored $m e^{\prime}$. In an example from study 3 , one participant recalled that her line manager expressed a preference to support male colleague's continued professional development since they were less likely to take sick leave, since she had been on leave as a result of gynaecological surgery. These examples of marginalisation from formal and informal groups reflect the exclusion interview participants described in the workplace and have important implications for career progression. Powell et al (2011) describe how women's exclusion from developing technical competence may have a number of consequences including reinforcing notions of difference between men and women, and perceptions that women are less capable than men. Exclusion from skill development also limits women's career progression, since it limits women's ability to accrue various forms of capital, which are necessary to reach more senior positions. Such exclusion is one form of symbolic violence through which gender inequality is reproduced in male-dominated professions.

A number of practicing architects (women) felt that they were excluded from informal networking opportunities, which were essential to attend if they wanted to bring new work into their practice (a necessity for progression). Women architects also experienced task restriction, which meant they were unable to demonstrate their technical skills (Sang et al., 2014), something that has been demonstrated in other male-dominated occupations (e.g. 
Guerrier et al., 2009). Carolyn, a work placement student (study 1) described how she was not shown what to do when she first started the placement, despite the fact that she was a student on placement:

When I first joined it wasn't very structured, my learning. I had to pick up the job on the go. I would rather someone sat me down - which is what happened to everyone else. Everyone else has had a handbook, and I've just been pushed out.

Within study 3, many of the women interviewed felt that they had been treated differently from the outset of their careers. Notably, six reported that they had been asked about their plans to have children during interview, with one woman feeling that she had been denied two positions due to her status as a mother. However, younger women in study 3 did not report such experiences. One respondent felt that this change was the result of a new generation of ' 90 s men' who she felt were less gender biased.

Similarly other research about women in male-dominated occupations has found that women are repeatedly excluded from informal and formal networking opportunities (Barnard et al., 2010). Such exclusion is likely to mean that women in engineering and construction have less social capital in the workplace than their male colleagues (Kumra and Vinnicombe, 2010). This is also clear evidence of symbolic violence and the reproduction of gender difference, with women denied access to resources - namely networking opportunities that are key to performance both at work and at university.

\section{Othering through humour}

In studies 1 and 3, there was much discussion about the use of sexism through everyday humour. While sexist 'humour' undoubtedly reinforces negative gender perceptions, almost all interviewees who reflected on it, reported that sexist jokes needed to be understood as nothing personal and 'only' humour. For example, Hannah a civil engineering student (study 1) stated: 
Generally speaking people are having a laugh, trying to wind you up, trying to get a bit of a reaction from you and you've just got to sort of accept that's all they're doing ... and sort of laugh back at them.

Hannah went on to say:

A lot of it mostly is, you know, just bits of friendly banter. Most of it sadly from men that are about 50 so you have to, you have you take it. I mean ... you look at these guys and if they thought that you thought they were being serious I think they would drop down on the spot. Because it's only ever joking and sort of more affectionate I think in a way, like they're sort of looking out for you.

Such humour is notoriously difficult to challenge, particularly for those that are the subject of it (i.e. women). In the example above Hannah is simultaneously recognising this behaviour as gendered, but arguing for its acceptability, if not inevitability. Another student in study 1 , Sophie, described how, on starting her industrial placement, she needed to show her male colleagues that she wasn't going to stop them from having a laugh and a joke:

I would probably join in with it nine times out of ten, and I can honestly say that I was never offended through anything at all they said in banter or sexually or anything.

It was up to Sophie to show she wasn't that different to the men and that she could 'take a joke,' before she felt that she was accepted.

Faulkner (2005) maintains that while many would argue that humour is 'only words', it sends powerful subliminal messages to both women and men. In other words, humour is a mechanism of social exclusion (Watts, 2007) and arguably another form of symbolic violence, particularly given its importance for maintaining men's homosociality in the workplace (Fisher and Kinsey, 2014). Lyman (1987: 150) describes humour as 'a theatre of domination in everyday life, and the success or failure of a joke marks the boundary within which power and aggression may be used in a relationship'. Humour is a means of embedding risky or 
unacceptable behaviour in superficially harmless statements, thus allowing the dominant figure to maintain authority while continuing to appear friendly (Holmes, 2000). Similarly Kanter (1977) argued that in allowing themselves to be a source of humour for the dominant group, women can demonstrate their loyalty. Both of these factors likely contribute to women's acceptance of workplace humour. Further, a 'good sense of humour' is a key aspect of what Friedman (2011: 347) calls 'comic cultural capital', a development of Bourdieu's conceptualisation of cultural capital. Watts (2007) also suggested that humour can be used to resist or challenge authority. However, we found little evidence of women using humour to subvert power structures, a phenomenon which Holmes (2000) describes as 'contestive' humour.

\section{(Mis)recognition of gendered treatment}

Women across the studies recounted examples of differential treatment as a result of their gender. In a similar vein to the responses to sexist humour, women's explanations for this frequently justified the differentiation as natural or to be expected. Hayley (study 1), a mechanical and manufacturing engineering student on placement spoke of the need to give male colleagues time to get used to having a woman in the workplace. She justified this by explaining that most 'guys have been working there for 30 years and haven't worked with a girl before'. She went on to say that as long as women acted 'normally' and demonstrated that they didn't need to be treated with 'kitten gloves', the men would get used to working with women. Gendered treatment is justified by women because men are not familiar with having women around. The implication is that this behaviour may change over time if more women enter male-dominated roles. What is also evident is that the emphasis is on women 'fitting in' with their male colleagues and not vice versa.

In further evidence of women's complicity with the dominant gender discourse, a number of participants justified the lack of women in engineering and construction due to innate gender differences between men and women. For example Andrea a civil engineering student (study 1) felt that women (generally) were unsuited to site based work: 
Although there are some women out there who want to go and play in the mud and enjoy surveying all day long, most women don't and that's because of fundamental differences between women and men.

Katie, a practicing architect (study 2 ) was passionately opposed to equality campaigns within the architectural profession which were intended to increase the proportion of women architects in practice. Katie felt that as a woman in her early 30s she was a 'complete liability' for an architectural practice. She went on to explain that 'maternity leave' can cripple a small practice and that:

[The] boys here are stronger at design and probably [stronger] technically...women and men argue it differently. They're [men] kind of more ballsy and, you know, they use long words that they don't know what they mean and things like that.

During the same exchange, Katie went to explain that she felt 'girls' were more emotional than 'boys' and the 'world isn't equal, we don't have 50\% of anything as far as I know:50/50 in nature?...we're actually built differently, were not naturally designed to do the same things'. Katie had also refused to join any women's networking groups because she was opposed to 'that kind of thing' despite feeling isolated due to being the only 'girl' in her office.

The women in the research predominantly viewed their experiences as unrelated to their gender. Yet at the same time, they subscribed to gendered notions that women are not suited to careers in engineering and construction because of innate gender differences between men and women. As noted above there were examples of women explicitly expressing gendered views of women and their suitability for work in the sector. While these perceptions pervade, there is likely to be little resistance to the status quo. For example, Sarah, a chemical engineering student on placement reported that she thought men were often better at engineering because men and women think about problems in different ways. This illustrates how symbolic violence embeds the naturalisation of gender differences (Gracia, 2009; Webb et al., 2002). In another example, Holly, a manufacturing student said: 
I'd rather work with men ... because the women on our course are all quite dictating. I do find it hard working with them because I think, in general, you tend to have similar qualities and it just gets quite difficult and it's easy when it's just one girl and a couple of men in my sort of class.

This characterisation of essentialised gendered differences can be related to developments on Bourdieu's conceptualisations of cultural capital. Huppatz (2009) has argued that feminine capital, a type of cultural capital because it is a learned competency, is valued within feminized occupations. In contrast, the current study demonstrates perceptions amongst some women that men are more suited to the 'masculine professions' because they have masculine capital i.e. stereotypically masculine skills and capacities, which enable men to be better engineers, architects etc. The naturalisation of masculine capacities means that masculine skills are seen as innate rather than acquired, which likely diminishes women's self-confidence in these areas. Further, we can see here that these women differentiate themselves from other women, perhaps suggesting that because they are able to survive within a masculine environment, they perceive themselves as better than other women, who work in other industries or perhaps do not work at all. In part this links to what McRobbie (2004: 106) calls 'new forms of class differentiation', whereby a culture of individualisation means that new social divisions are being created as women compete with each other.

As we have demonstrated above and elsewhere (Sang et al., 2014), women can be complicit in the social construction of identities that ultimately marginalise them. Volman and Ten Dam's (1998) study found that for the young people in their study gender differentiation was a significant element of their everyday interactions, but that they struggled to make sense of those differences without appearing to endorse inequality. Instead, gender-specific behaviours and preferences are interpreted as the product of individual choice. Budgeon (2014) suggests that new femininities are associated with a heightened emphasis on individual responsibility, the ideological de-gendering of social relations and a position within the gender binary consistent with the workings of a hegemonic form of femininity.

Bourdieu argues that the process by which individuals fail to recognise the social origins of symbolic violence is misrecognition, which lies outside of conscious thought (Schubert, 
2008). Misrecognition is useful when considering symbolic violence as it allows for analysis of how women may perceive their experiences as the natural order of things, rather than recognising discrimination as a form of violence. As such, misrecognition is key to symbolic violence (Bourgois et al., 2004). However, it is necessary not to 'blame' women for this recognition, as this in itself would be a form of symbolic violence (Schubert, 2008).

\section{Female capital?}

A number of women recounted workplace examples where they perceived being a woman was an advantage. At face value, this may be evidence of what Huppatz (2009) calls female capital. These advantages reportedly included more help or support in the laboratory/workplace compared to men, and positive discrimination for women job applicants. Within study 3 some women respondents reported they enjoyed being the only woman on a construction site as it increased their visibility and had career benefits. Others felt they were able to mobilise their femininity to rely on traditionally 'chivalrous' gestures from men, such as buying drinks after work. Occasionally these advantages appeared to be leveraged deliberately, other times women seemed to have less control over the situation. For example, Alison (study 1), a mechanical and manufacturing engineering student described how men in the storeroom were more willing to help her than her male colleagues. Others spoke about deliberately adopting stereotypically female behaviour in order to get this kind of help. For example Isabella, a mechanical and manufacturing engineering student on placement (study 1 ), said:

Sometimes I sort of play up to being a bit ditzy so I can get a bit more help and if you play up to being ditzy then they don't actually mind doing the help so much. I get a lot of help here but I don't know how much a guy would get. I don't know how much they would be told to get on with it and stop being such a girl.

This relates to what Huppatz (2009) calls 'feminine advantage'. She calls this female capital (not feminine capital), since women are actively making the female matter. Equally, however, Huppatz also notes that female capital does not dominate male capital. Further, as 
previous research has demonstrated women may actively participate in gendered ways of working which reproduce gender inequality, which is ultimately to their disadvantage (Powell et al., 2009; Sang et al., 2014).

Positive discrimination was seen as a particular feature in relation to gaining access to jobs, since companies were perceived to be trying to boost their gender diversity. Jenny, an aeronautical and automotive engineering student (study 1), described how she believed being a woman gave her a better chance at a job than a man with the same qualifications and experience, because 'they've got to employ a certain percentage of women'.

This also had an othering effect and two of the interviewees in study 1 , from different disciplines, went on to say that as a result of this experience (of being favoured) they questioned their own abilities. Rebecca, a design and technology student, for example, said:

I've always felt like I don't know if I would have got on this course if I'd been a bloke ... They didn't even look at my work, so they couldn't have known, and every bloke I've spoken to has had a really vigorous interview.

Such perceptions of positive discrimination may reinforce notions that women are less capable than men, because others may believe that they were employed on the basis of their gender, rather than being the best candidate for the position. It may also serve to undermine women's cultural capital.

Data from study 3 suggested that this type of differential treatment was in part a reflection of women's novel status within male-dominated professions. Namely their treatment as tokens, which women articulated as resulting in increased visibility. As such, seven of the women argued that they were subject to harsher evaluations than male colleagues due to this visibility.

\section{Resisting gendered norms}

In contrast to the younger women in studies 1 and 3, most women in Study 2 did not naturalise gender differences, or the resulting differences in behaviour. In contrast to study 1 , the participants in study 2 were older and had been in employment for longer. In addition, 
a number of respondents were actively engaged in gender equality initiatives within the architectural profession. Even among some younger participants, there were a few women who were more conscious of the effects of gendered norms and being treated differently. Debra, a quantity surveying student (study 1), for example, reflected on how she was expected not to act in traditionally feminine ways, yet was simultaneously criticised for behaving in the same way as her colleagues, because this was seen as inappropriate. This illustrates the impossible situation that women in male-dominated spheres are faced with:

I felt, when I was working that they didn't, it was weird because I felt like they only employed me because I was a girl and yet they didn't want me to act feminine. And so when I was going out for drinks and stuff it was always, everyone kind of frowned upon it. I was trying to be like one of the lads, you know, but they took it as I was going on all these dates and things ... they just didn't want me to act feminine.

This quote highlights what Bourdieu (2001) calls a 'double bind' for women; if women behave like men, they risk their 'feminine' attributes and implicitly question men's power, if they behave like women, 'they appear incapable and unfit for the job' (2001: 68). It is also evidence that women are limited in the types of capital they can convert to other capital (Reay, 2004b), such that while women may hold female capital and cultural capital, this is not the same as, nor can it be converted to, male capital, at least not in the male-dominated professions.

Natalie, an architectural engineering student (study 1 ) also reflected on the fact that women are treated differently:

There are men out there that still think that they're better than women. And I think it's very important that women have to be educated on the fact that they're going to be treated differently, although it's hard and you shouldn't be, I think you have to be aware that you're different.

Women sought to overcome any perceived discrimination or negative attitudes about their gender by competing with male students to demonstrate that they were good, capable 
engineers, who had earned the right to be an engineer and who were 'just as intelligent as the person sitting next to you' (Emily, Aeronautical \& Automotive engineering student, study 1). For example, Holly said:

To some extent, you've just got to kind of go and show them that you can do something. It's just that you've got to prove yourself to them, I think. I think that you've gotta like work harder and show that you actually do know something and you do use your initiative a bit more.

Having said that, another student, Chloe (study 1 ), stated that she felt that once she had proven herself, any barriers she had felt previously were removed. Similar to 'acting like one of the boys', the women appeared to believe that by proving their ability to be 'good engineers' their gender would be insignificant. This is something of a paradox given that the women also felt they had to work harder than their male peers entirely to overcome the fact that they were women, something which is well established by others in this area (Fowler and Wilson, 2004).

On the whole, even when women recognised gender was an issue, there was minimal resistance of the dominant power structures. In part this may result from women's assimilation into their industries (e.g. Powell et al., 2006), but is also likely because challenging everyday sexism risks further exclusion or isolation (Whittock, 2002). Lawler (2004), drawing on Bourdieu, suggests that the lack of resistance is because 'people are not fools' - they behave in ways that are consistent with their habitus and their field. In other words, resistance would be foolish given their context. She also suggests that it may be more liberating for people to 'cast off' their 'marks of difference and to adopt a normalised habitus' (Lawler, 2004: 122), rather than to challenge the status quo. Again this suggests that by behaving in a way consistent with cultural norms, rather than resisting or challenging those norms, women are attempting to minimise perceived differences with men.

However, resistance does not have to be overt (Prasad and Prasad, 1998), and there was evidence of small, everyday acts of defiance, such as Katie (study 1), who spoke of resisting 
gendered expectations. She described deliberately making a bad cup of tea for her colleague so she would not be asked to do it again:

When I first arrived [on placement], one of the old engineers ... was like “Oh. You know you're student and you're a girl, why aren't you making the tea?" And I laughed. And then I realised he wasn't laughing. And I thought, "Oh God". So I made him a cup tea and I deliberately made the worst cup of tea ever. And the tea bag hardly touched the water. And he never asked me to make him a cup of tea again.

Such subtle acts of everyday resistance may be the safest strategy for women, as well as acknowledging what is 'possible and achievable, and what was fruitless and pointless' (Anderson, 2008: 261). Nevertheless, as Bourdieu has noted, while acts such as this may give women some room for manoeuvre (Lovell, 2004), 'the weapons of the weak are weak weapons' (Bourdieu, 2001: 32).

\section{Conclusions}

This paper has drawn on three qualitative studies of women engineering students and practising architects' everyday experiences of working in male-dominated professions. In doing so it has demonstrated the value of Bourdieu's concepts of symbolic violence and misrecognition. In particular, these are useful tools for understanding the experience and awareness of everyday sexism within these male-dominated occupational contexts. This helps to elucidate how and why women in engineering and construction continue to be under-represented and dominated by men. It is also valuable in a broader sense since it shows how the sociology of everyday life can reveal something about the practice and processes of gender (Crow and Pope, 2008; Peel, 2001).

The data reveal that women's difference from men is reiterated and experienced as a matter of routine. Indeed its routineness, or everyday nature, has rendered this sexism largely invisible for younger women. The concept of misrecognition is valuable in understanding why women in engineering and construction do not challenge this difference or 'othering', since it is often misrecognised as natural or innate (Webb et al., 2002). Thus as Miller (2002) has 
argued there is often 'an unawareness of the masculine nature of the context'. This contrasts with popular discourses of 'everyday sexism' where it is recognised and publically articulated as such (Bates, 2014). The data demonstrated several occurrences of women feeling marginalised or excluded, although further work is required to understand the strategies employed by those women who do not 'misrecognise' gendered relations, which would help to develop Bourdiusian analyses (Adkins and Skeggs, 2004). Similarly other research about women in male-dominated occupations has found that women are repeatedly excluded from informal and formal networking opportunities (Barnard et al, 2010). Such exclusion is also likely to mean that women in engineering and construction have less social capital in the workplace than their male colleagues (Kumra and Vinnicombe, 2010). We can clearly see here instances of symbolic violence against women engineering and construction students and professionals with denial of access to resources - namely networking opportunities that are key to performance both at work and at university. As such this can place limits on both their capacity and aspirations for progression, or even to remaining in the workforce.

Modern prejudice and discrimination against women has become increasingly subtle and covert (Benokraitis and Feagin, 1986) meaning that it is harder for women to identify instances of discrimination as such (see also Martin, 2006). This can be particularly significant in terms of humour, where sexist attitudes were commonly expressed. Holmes (2000) for example, suggests that unacceptable behaviour embedded in superficial humour, is particularly difficult to challenge because the joker remains friendly and it is likely to be the challenger that is ostracised by colleagues for 'not taking the joke'.

Witz (2004), and others, have argued that symbolic violence paints women as compliant and shifts the burden of responsibility for women's oppression from men to women themselves (Witz, 2004). However, we suggest that it highlights the importance of including men in any policy initiatives to address women's under-representation and discrimination, since women, usually unconsciously, can be complicit in their domination. As Bourdieu (2000) argues, complicity is not a conscious, deliberate act, 'it is itself the effect of power'. This also reflects women's assimilation into the masculine culture of engineering and construction (see also Dryburgh, 1999; Walker, 2001; Miller, 2002; Powell et al., 2009). Such assimilation 
occurs when women learn the rules of the game. In other words, and borrowing again from Bourdieu, women learn the 'habitus', that is the values and dispositions, of the engineering and construction 'field', and that this field is intrinsically male and respond accordingly. Analysis of the experiences of women in engineering and construction using Bourdieu's concepts of habitus and field will be the focus of future publications. This is also likely a result of the very low numbers of women in engineering and construction, which results in women individualising their negative experiences rather than perceiving them as a result of gender. In other industries where women represent a more sizeable minority, such as science, this may not be the case. This will be the subject of future research. However, as the data suggests, the individualisation of discrimination may also result in perceived divisions between women. Drawing on McRobbie (2004) these created divisions may rest, in part, on perceived class differentials. The women in the studies considered here were all of relative privilege, being university educated and working in professional fields. Further work is required to understand how gender relations are maintained along class lines, particularly in light of recent research highlighting the fragility of gendered identities for women working in the manual trades (Smith, 2013).

These findings also call into question existing policy recommendations in the Western hemisphere that argue women have different skills that can be brought to the sector (such as co-operation) (e.g. Barnard et al., 2010), as well as those that focus on increasing numerical diversity rather than achieving genuine inclusivity (Sang and Powell, 2012). Such policies reinforce the gendered nature of the engineering and construction sectors' habitus and fail to recognise how the underlying structures and practices of the sector reproduce gendered working practices.

This research has explicitly focused on the everyday lived experiences of women in a maledominated industry. Future research should examine the experiences of men in this context in order to consider how they practice symbolic violence and misrecognition. Any such future studies should be aware that the category of 'men' is not homogeneous. The framework of symbolic violence would enable an analysis of how the sector perpetuates inequalities against non-dominant men, for example, ethnic minority men or gay men. Further research 
should also explore how symbolic violence occurs in sectors that are less male-dominated and where the organisational culture is likely to be different.

\section{Acknowledgements}

The authors would like to thank the participants that took part in this research, as well as Professors Barbara Bagilhole, Andrew Dainty, Stephen Ison (Loughborough University, UK) and Andrew Munns (University of Dundee, UK), who were involved in the original research projects on which this paper is based, for their ongoing support.

\section{References}

Adkins L, Skeggs B (eds) (2004) Feminism after Bourdieu. Oxford: Blackwell, 3-18.

Anderson G (2008) Mapping academic resistance in the managerial university. Organization 15(2): 251-270.

Barnard S, Powell A, Bagilhole B and Dainty A (2010) Researching UK women professionals in SET: a critical review of current approaches. International Journal of Gender, Science and Technology 2(3): 361-381.

Bates L (2014) Everyday Sexism. London: Simon and Schuster.

Becker JC, Swim JK (2011) Seeing the Unseen Attention to Daily Encounters With Sexism as Way to Reduce Sexist Beliefs. Psychology of Women Quarterly 35(2): 227-242.

Benokraitis NV, Feagin JR (1986) Modern sexism: blatant, subtle and covert discrimination. Harlow: Prentice Hall.

Berg SH (2006) Everyday sexism and posttraumatic stress disorder in women. Violence Against Women 12(10): 970-988.

Bolton SC, Muzio D (2007) Can't Live with 'Em; Can't Live without 'Em Gendered Segmentation in the Legal Profession. Sociology 41(1): 47-64. 
Bourdieu P (1986) Force of law: toward a sociology of the judicial field. The Hastings Law Journal 38: 805.

Bourdieu P (2000) Pascalian Meditations. Cambridge: Polity Press.

Bourdieu P (2001) Masculine domination. Cambridge: Polity Press.

Bourdieu P, Wacquant L (1992) An invitation to reflexive sociology. Chicago: Chicago University Press.

Bourgois P, Prince B and Moss A (2004) The Everyday Violence of Hepatitis C Among Young Women Who Inject Drugs in San Francisco. Human Organization 63(3): 253-264.

Cockburn C (1991) In the way of women: men's resistance to sex equality in organisations. London: Macmillan.

Crow G, Pope C (2008) Editorial Foreword: Sociology and Everyday Life. Sociology 42(4): 597600.

Dryburgh H (1999) Work hard, play hard: women and professionalization in engineering adapting to the culture. Gender \& Society 13(5): 664-682.

Everingham C, Stevenson D and Warner-Smith P (2007) 'Things are getting better all the time?' Challenging the narrative of women's progress from a generational perspective. Sociology 41(3): 419-437.

Faulkner W (2005) Becoming and belonging: gendered processes in engineering. In: Archibald J, Emms J, Grundy F, Payne J and Turner E (eds) The gender politics of ICT. Middlesex: Middlesex University Press, 15-25.

Fisher V, Kinsey S (2014) Behind closed doors! Homosocial desire and the academic boys club. Gender in Management: An International Journal 29(1): 44-64.

Fowler B, Wilson E (2004) Women architects and their discontents. Sociology 38(1): 101-119. 
Friedman S (2011). The cultural currency of a 'good'sense of humour: British comedy and new forms of distinction. The British Journal of Sociology 62(2): 347-370.

Gervais SJ, Hillard AL and Vescio TK (2010) Confronting sexism: the role of relationship orientation and gender. Sex Roles 63(7-8): 463-474.

Gracia L (2009) Employability and higher education: contextualising female students' workplace experiences to enhance understanding of employability development. Journal of Education and Work 22(4): 301-318.

Guerrier T, Evans C, Glover J, et al. (2009) 'Technical, but not very...': constructing gendered identities in IT-related employment. Work, Employment \& Society 23(3): 494-511.

Hammersley M (2010) Can we re-use qualitative data via secondary analysis? Notes on some terminological and substantive issues. Sociological Research Online 15(1): 5.

Holmes J (2000) Politeness, power and provocation: how humour functions in the workplace. Discourse Studies 2(2): 159-185.

Huppatz K (2009) Reworking Bourdieu's 'Capital': Feminine and Female Capitals in the Field of Paid Caring Work. Sociology 43(1): 45-66.

Kanter RM (1977) Men and women of the corporation. New York: Basic Books.

Kumra S, Vinnicombe S (2010) Impressing for Success: A Gendered Analysis of a Key Social Capital Accumulation Strategy. Gender, Work \& Organization 17(5): 521-546.

Lawler S (2004) Rules of engagement: Habitus, power and resistance. The Sociological Review 52(s2): 110-128.

Lovell T (2000) Thinking feminism with and against Bourdieu. Feminist Theory 1(1): 11-32.

Lovell T (2004) Bourdieu, class and gender: 'The return of the living dead'? The Sociological Review 52(s2): 35-56. 
Lyman P (1987) The fraternal bond as a joking relationship: a case study of the role of sexist jokes in male group bonding. In: Kimmel MS (ed) Changing men: new directions in research on men and masculinity. Newbury Park, CA: Sage, 148-163.

Martin PY (2006) Practicing gender at work: further thoughts on reflexivity. Gender, Work and Organization 13(3): 254-276.

McCall L (1992) Does gender fit? Bourdieu, feminism and conceptions of social order. Theory and Society 21(6): 837-867.

McRobbie A (2004) Notes on 'What Not To Wear' and post-feminist symbolic violence. The Sociological Review 52(s2): 97-109.

Miller GE (2002) The frontier, entrepreneurialism and engineers: women coping with a web of masculinities in an organizational culture. Culture and Organization 8(2): 145-160.

Moi T (1991) Appropriating Bourdieu: Feminist Theory and Pierre Bourdieu's Sociology of Culture. New Literary History 22(4): 1017-1049.

Nkomo SM (1992) The emperor has no clothes: rewriting 'race in organizations'. The Academy of Management Journal 17(3): 487-513.

Peel E (2001) Mundane heterosexism: understanding incidents of the everyday. Women's Studies International Forum 24(5): 541-554.

Pink S (2012) Situating Everyday Life. London: Sage.

Powell A, Bagilhole B and Dainty A (2006) The problem of women's assimilation into UK engineering cultures: can critical mass work? Equal Opportunities International 25(8): 688-699.

Powell A, Bagilhole B and Dainty A (2009) How women engineers do and undo gender: consequences for gender equality. Gender, Work and Organization 16(4): 411-428. 
Powell A, Dainty A and Bagilhole B (2011) A poisoned chalice? Why UK women engineering and technology students may receive more 'help' than their male peers. Gender and Education 23(5): 585-599.

Prasad A, Prasad P (1998) Everyday Struggles at the Workplace: The Nature and Implications of Routine Resistance in Contemporary Organizations. In: Bamberger PA and Sonnenstuhl WJ (eds) Research in the Sociology of Organizations: Deviance in and of Organizations. London: JAI Press, 225-257.

Reay D (2004a) 'It's all becoming a habitus': beyond the habitual use of habitus in educational research. British Journal of Sociology of Education, 25(4): 431-444.

Reay D (2004b) Gendering Bourdieu's concepts of capitals? Emotional capital, women and social class. The Sociological Review 52(s2): 57-74.

Sang KJC and Powell A (2012) Equality, diversity, inclusion and work-life balance in construction. In: Dainty A and Loosemore M (eds) Human Resource Management in Construction: Critical Perspectives. Abingdon: Routledge, 163-196.

Sang KJC, Dainty A and Ison SG (2014) Gender in the UK architectural profession: (re)producing and challenging hegemonic masculinity. Work, Employment \& Society 28(2): 247-264.

Sayer A (2005) Class, moral worth and recognition. Sociology, 39(5): 947-963.

Schippers M (2007) Recovering the feminine other: masculinity, femininity and the gender order. Theory and Society 36(1): 85-102.

Schubert JD (2008) Suffering /symbolic violence. In: Grenfell M (ed) Pierre Bourdieu Key Concepts. Stocksfield, UK: Acumen Publishing, 183-198.

Skeggs B (2004) Context and Background: Pierre Bourdieu's analysis of class, gender and sexuality. The Sociological Review 52(s2): 19-33. 
Smith DE (1987) The Everyday World as Problematic: a feminist sociology. Boston, MA: Northeastern University Press.

Smith L (2013) Trading in gender for women in trades: embodying hegemonic masculinity, femininity and being a gender hotrod. Construction Management and Economics 31(8): 861-873.

Van den Berg H (2008) Reanalyzing qualitative interviews from different angles: The risk of decontextualization and other problems of sharing qualitative data. Historical Social Research/Historische Sozialforschung 33(3): 179-192.

Walker M (2001) Engineering identities. British Journal of Sociology of Education 22(1): 7589.

Watts J (2007) Can't take a joke? Humour as resistance, refuge and exclusion in a highly gendered workplace. Feminism and Psychology 17(2): 259-266.

Webb J, Schirato T and Danaher G (2002) Understanding Bourdieu, Crows Nest: Allen and Unwin.

Whittock M (2002) Women's experiences of non-traditional employment: is gender equality in this area possible? Construction Management and Economics 20(5): 449-456.

Witz A (1990) Patriarchy and professions: the gendered politics of occupational closure. Sociology 24(4): 675-690.

Witz A (2004) Anamnesis and amnesis in Bourdieu's work: The case for a feminist anamnesis. The Sociological Review 52(s2): 211-223. 


\section{Biographies}

Abigail Powell is a Senior Research Fellow at the Centre for Social Impact, UNSW Australia. Abigail's research interests are in gender, diversity, work-life balance, young people and social policy. Abigail currently holds two Australian Research Council grants; the first is an early career fellowship investigating whether flexible work arrangements promote work-life balance for employees in Australia; the second is an industry partnership grant examining gender equity and diversity in the Australian construction sector.

Katherine Sang is an Associate Professor of Management at Heriot-Watt University in Edinburgh (Scotland). Her research interests include the workplace as a site where gender in (re)produced. Using intersectional and relational lenses, she explores how gender intersects with other social identities, (including disability, ethnicity and migratory status) to understand patterns of privilege and disadvantage in the workplace. In addition to this research, Kate is the Chair of the Feminist and Women's Studies Association UK \& Ireland. Along with Rebecca Finkel, Kate established Scottish Feminist Academics in 2012. In 2010 Kate launched Feminist Academics International, a global network for feminist academics. 